\title{
TEORIA DAS FUNDAÇÕES MORAIS: O NATIVISMO MORAL EM JONATHAN HaIDT
}

\author{
Moral foundations theory: Haidt's Moral Nativism
}

RESUMo Jonathan Haidt propôs uma das versões mais conhecidas de nativismo moral, na qual ele defende a existência de certas fundações morais. Neste artigo, examino as principais críticas feitas a essa teoria, em especial a) a de que Haidt estaria comprometido com uma tese bastante questionável acerca da mente humana; e b) a de que a descrição de Haidt seria incompleta, em razão de não fornecer uma explicação para as etapas mentais prévias ao desencadeamento das intuições. Quanto à primeira crítica, ao aceitar a tese da modularidade massiva, Haidt de fato se compromete com uma visão a respeito da mente humana que não é consiliente com os resultados de pesquisas neurocientíficas. No entanto, em razão de ter ciência dessa objeção, ele propõe para os críticos da modularidade massiva uma versão mais amena de sua teoria. Com relação à segunda crítica, a teoria de Haidt é realmente incompleta, pois ignora que só é possível que uma ação produza determinada intuição após aquele que a percebe ter formado algum tipo de representação. A partir da análise dessas críticas, concluo que a teoria das fundações morais, em sua versão amena, oferece uma explicação plausível para os julgamentos morais, mas falha ao não oferecer uma explicação acerca do papel que inferências sobre os estados mentais do autor da ação desempenham no desencadeamento das intuições morais.

PALAVRAS-CHAVE: INATISMO. MORALIDADE. FUNDAÇÕES MORAIS. MODULARIDADE DA MENTE. INTUICIONISMO.

ABSTRACT Jonathan Haidt proposed one of the most well-known versions of moral nativism, in which he defends the existence of certain moral foundations. In this paper, I examine the main criticisms of this theory, especially a) the claim that it implies a questionable thesis about the human mind; and b) that Haidt's description is incomplete inasmuch as it does not provide an explanation for the mental steps prior to the triggering of intuitions. As for the first criticism, in accepting the thesis of massive modularity, Haidt commits himself to a view of the human mind that is not consilient with the results of neuroscientific research. Nevertheless, since he is aware of this objection, he proposes a milder version of his theory to counter the critics of massive modularity. Regarding the second criticism, Haidt's theory is, in fact, incomplete; for it ignores that it is only possible that an action provokes an intuition after the observer has formed some kind of representation. From the analysis of these criticisms, I conclude that the Moral Foundations Theory, in its mild version, offers an apparently plausible explanation for moral judgments. Notwithstanding, Haidt's theory fails in some measure. It does not explain the role that assumptions about the mental states of the author of an action play in triggering moral intuitions.

KEY-WORDS: INNATISM. MORALITY. MORAL FOUNDATIONS. MODULARITY OF MIND. INTUITIONISM.
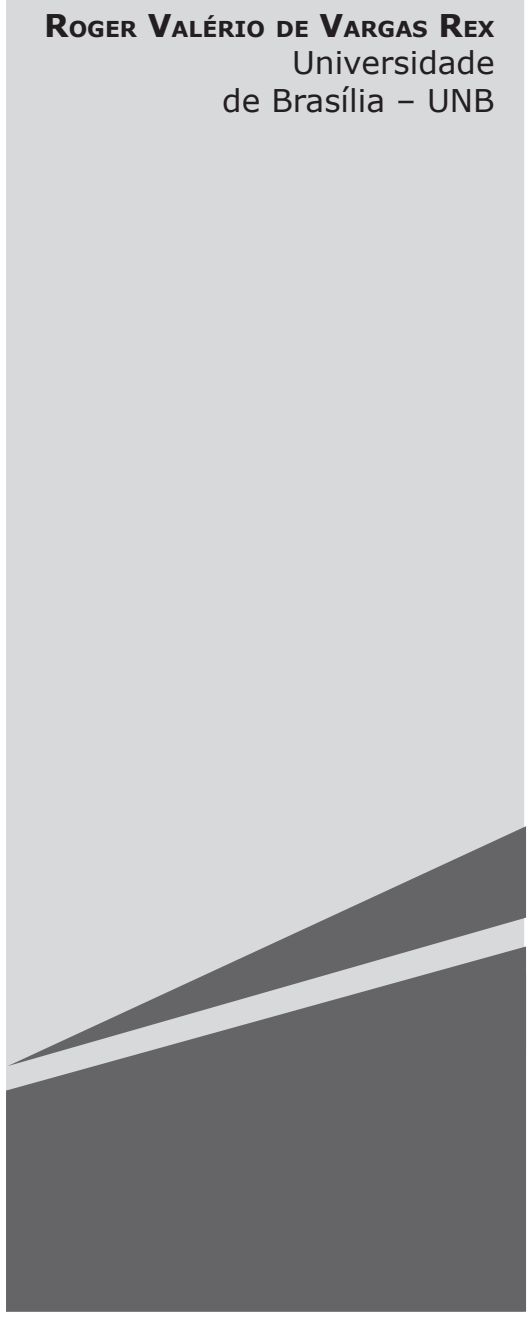
INTRODUÇÃo

$\mathrm{N}$ a tradição filosófica ocidental, discussões sobre a existência de conhecimentos inatos já ocorrem, pelo menos, desde Platão. No diálogo Mênon, por exemplo, ele sustenta a doutrina nativista da anamnese, ou seja, a ideia de que todo aprendizado é apenas uma forma de recordação de algo que já estava em nós antes mesmo de recebermos qualquer ensinamento (2005, p. 112-137). No entanto, o debate nativista realmente acirrou-se com o ataque de Locke (1995), nos primeiros capítulos de seu Ensaio sobre o Entendimento Humano, àqueles que defendiam a existência de princípios ou ideias inatas. A posição de Locke, apesar de criticada por filósofos como Leibniz, acabou triunfando: as ciências modernas se desenvolveram à luz de um empirismo antinativista; e a doutrina das ideias inatas passou a ser vista como retrógrada, não-científica, inextricável de outras doutrinas metafísicas e teológicas que caíram em descrédito, e incompatível com uma abordagem naturalista acerca da natureza humana (SAMET, 2008).

Entretanto, esse quadro começou a sofrer grande alteração em razão dos trabalhos publicados pelo linguista Noam Chomsky, a partir dos anos de 1950 (1965; 1975; 1986). Chomsky defendeu que a melhor explicação para a aquisição da linguagem era a existência de um conjunto de conhecimentos inatos, chamado de "Gramática Universal", que tornaria possível o aprendizado da linguagem, mesmo diante da pobreza de estímulos. Após as pesquisas de Chomsky, cientistas cognitivos passaram a aderir a explicações nativistas sobre o desenvolvimento das capacidades cognitivas - rejeitando a teoria da tabula rasa de Locke - e a defender que conteúdos mentais estão presentes desde o nascimento. Hoje, afirmam, por exemplo, que mecanismos inatos desempenham importantes papéis nas nossas habilidades para explicar e prever 0 movimento de objetos físicos de tamanho médio (SPELKE, 1988) e para classificar animais e plantas (ATRAN, 1998).
Em conformidade com essa tendência, há alguns anos filósofos e cientistas retomaram o debate sobre o papel de estruturas inatas na moralidade. Esse debate adota como ponto de partida a observação de que os seres humanos de diversas culturas classificam características comportamentais a partir de normas e valores morais. A questão que, então, se coloca e em torno da qual o debate se desenvolve é: de onde vem essa forma normativa de pensar?

Neste artigo, analiso a resposta nativista que Jonathan Haidt oferece para essa questão. Haidt defende a existência de certas fundações morais. De acordo com essa hipótese, apesar das grandes variações existentes entre as normas presentes nas diversas culturas, haveria certas intuições morais derivadas do conjunto das emoções inerentes aos seres humanos. Essas intuições, produzidas a partir de módulos mentais específicos, favoreceriam o surgimento de normas morais sobre determinados temas como reciprocidade, equidade, cooperação, condutas lesivas etc. Após expor brevemente a teoria proposta por Haidt para explicar a aquisição da moralidade, examino as principais críticas feitas a essa teoria.

\section{O PAPEL DAS FUNDAÇÕES MORAIS NA AQUISIÇÃO DA MORALIDADE}

A moralidade existe em todas as sociedades humanas de que temos conhecimento e em praticamente todo indivíduo, desenvolve-se sem instrução formal e sem esforço deliberado (JOYCE, 2006; AYALA, 2010, p. 2). Jonathan Haidt elaborou a sua Teoria das Fundações Morais (TFM), a partir dessa constatação. Haidt analisou listas de virtudes existentes ao redor do mundo e percebeu algumas semelhanças e superposições. Em diferentes culturas, os indivíduos apresentam alguns dos mesmos tipos de reações automáticas e emocionais às interações sociais (EKMAN et al., 1969). Com base nisso, psicólogos e antropólogos culturais já haviam proposto que os sistemas morais são ancorados em um pequeno 
conjunto de valores morais universais (e.g., ROZIN et al., 1999; SHWEDER et al., 1997).

Haidt, então, começou a se perguntar se não haveria, no âmbito da moral, algo semelhante aos receptores que temos para perceber os sabores. Ele ilustra essa analogia da seguinte forma: na grande maioria das culturas há um ou mais tipos de bebidas doces que são largamente consumidas, normalmente derivadas de frutas locais ou, nos países industrializados, de açúcar e aromatizantes. Seria absurdo imaginar que temos diferentes receptores para suco de manga, suco de maça e Coca-Cola. Há no caso em questão apenas um tipo de receptor capaz de identificar sabores adocicados, mas cada cultura inventa diferentes formas de acioná-lo.

No âmbito da moral, apesar da variação cultural de normas e práticas, haveria um pequeno conjunto de intuições morais facilmente encontráveis em todas as sociedades, mas que poderiam ser desencadeadas de diversas formas, conforme as variações culturais. As nossas mentes têm o potencial para incluir as mais diversas práticas nos domínios da moral. No entanto, apenas algumas dessas práticas, a partir de nossas experiências culturais, serão incluídas, ao longo de nossa infância, naquilo que compreendemos por moralidade. Outras tantas práticas permanecerão desconectadas daquilo que forma a rede de valores e sentidos compartilhados que compõem a nossa matriz moral (HAIDT, 2012, cap. 5).

As cozinhas são produtos da cultura e cada uma é única e possui um conjunto de ingredientes principais. No entanto, elas são construídas a partir de um sistema sensorial que inclui apenas cinco tipos de receptores para os gostos e de um sistema olfativo mais complexo. Os tipos de papilas gustativas trazem óbvios benefícios adaptativos: o sabor doce é útil para reconhecer frutas e indicar que o alimento é seguro; o sabor amargo indica a presença de toxinas e alerta para o perigo; o receptor de glutamato indica a presença de carne e assim por diante. A estrutura da nossa língua, de nosso nariz e do nosso cérebro estabelece restrições aos tipos possíveis de cozinha, mas deixa bastante espaço aberto à criatividade. A ideia de Haidt é que haveria algo semelhante no domínio da moral, ou seja, existiria um pequeno conjunto de intuições morais sob a grande diversidade de sistemas de normas morais (HAIDT \& BJORKLUND, 2008, p. 201-2). Tanto a moralidade quanto as diferentes cozinhas seriam construções culturais, influenciadas por diversos fatores históricos e ambientais, mas não seriam completamente flexíveis. Não podemos ter um tipo de cozinha ancorada em cascas de árvores ou predominantemente em sabores amargos, pois, para que uma culinária se estabeleça, ela precisa agradar línguas equipadas com uma variedade limitada de papilas gustativas. De modo semelhante, uma matriz moral precisa ser compatível com mentes equipadas com determinados tipos de receptores sociais (HAIDT, 2012, cap. 6).

Haidt e Joseph (2004) procuraram identificar, a partir de cinco pesquisas sobre características universais (BROWN, 1991; FISKE, 1992; SCHWARTZ \& BILSKY, 1990; SHWEDER et al., 1997; de WAAL, 1996), princípios comuns da moralidade humana. Após tentarem listar todas as coisas que humanos e chimpanzés pareciam valorar no comportamento dos outros, eles as dividiram em cinco categorias: a) sensibilidade ou aversão a sinais de dor e sofrimento em outros (harm/care); b) respostas negativas àqueles que falham em retribuir favores (fairness/reciprocity); c) raiva contra aqueles que falham em demonstrar sinais de deferência e respeito (authority/respect); d) emoções relacionadas a nojo e repulsa, necessárias para explicar regras morais sobre comida, sexo, menstruação e manuseio de cadáveres (purity/sanctity); e) atitudes em relação às fronteiras entre os grupos (in-group/out-group). ${ }^{1}$ Esses cinco grupos de intuições seriam as bases da moralidade (HAIDT \& BJORKLUND, 2008, p. 202-203) e cada um deles representaria um módulo mental e se relacionaria a diferentes famílias de emoções. O sofrimento provoca empatia e compaixão;

Em alguns trabalhos Haidt designa esse domínio "Loyalty/Betrayal Foundation" (HAIDT, 2012). 
desrespeito à hierarquia provoca ressentimento; violação da reciprocidade provoca raiva e culpa; violações relacionadas ao domínio da pureza provocam nojo. Essas fundações seriam universais, mas cada cultura poderia determinar os conteúdos específicos de cada uma delas (HAIDT \& JOSEPH, 2004).

Ao elaborar a sua teoria, Haidt procurou identificar as conexões entre as virtudes existentes e as teorias evolutivas bem estabelecidas (HAIDT, 2012, cap. 6). Ele buscou identificar os desafios adaptativos da vida social de nossos ancestrais e conectá-los às virtudes presentes de alguma forma em diversas culturas. Para cada uma das emoções e intuições associadas a essas virtudes, ele traçou uma história evolutiva que procura explicar quais eram as circunstâncias que as desencadeavam e, assim, estabelecer uma ligação entre as observações antropológicas e a Teoria Evolutiva, embora reconheça que as explicações por ele propostas para a origem das emoções sejam apenas "educated guesses".2

A tentativa de Haidt de explicar o surgimento das fundações morais a partir de uma perspectiva evolucionista enfrenta muitos desafios. As evidências que temos a respeito dos ambientes nos quais ocorreu a maior parte do processo de evolução de nossa espécie são bastante limitadas. Dessa maneira, é possível propor múltiplas histórias que sejam em alguma medida compatíveis com as evidências empíricas existentes, e a tarefa de avaliar qual dessas histórias é mais plausível envolve um grau elevado de especulação. Para os propósitos do presente artigo, basta destacar que, ainda que as histórias propostas por Haidt não tenham um embasamento empírico tão robusto quanto desejaríamos acerca da origem das fundações morais, há inúmeras pesquisas conduzidas por antropólogos e psicólogos que dão suporte à hipótese de que as normas morais existentes nas mais variadas culturas tendem a se agrupar em torno de

Para um estudo mais detalhado sobre as histórias evolutivas propostas por Haidt e a respeito das pesquisas científicas que lhe dão suporte, ver REX (2016a, cap. 5). certos temas. Ou seja, ainda que possa haver controvérsias significativas a respeito da origem dessas fundações, da melhor forma de categorizá-los e dos limites que os separam, é muito difícil negar que as normas morais existentes se agrupam em torno de certos temas.

Segundo Haidt, o agrupamento das normas morais seria o resultado de predisposições inatas que facilitariam o aprendizado de certas normas. Na área da psicologia, é universalmente aceito que algumas coisas são mais fáceis de aprender do que outras. É extremamente difícil moldar uma criança quando o esforço é feito em sentido contrário ao que elas gostam naturalmente. Não exige muito trabalho, por exemplo, fazer uma criança preferir balas a brócolis, a simpatia de outras crianças à aprovação de adultos, ou revidar uma agressão ao invés de amar os inimigos (HAIDT \& BJORKLUND, 2008, p. 2012). A ideia central desse tipo de modelo é que os seres humanos possuem fortes predisposições para desenvolver certas reações e preferências que exercem um papel causal sobre aquilo que consideramos permissível, proibido ou obrigatório no âmbito moral (GIROUX, 2011, p. 292-3).

A hipótese de que os seres humanos possuem determinadas predisposições (preparedness) para o aprendizado moral é reforçada por experiências que indicam o desenvolvimento precoce das percepções envolvidas nos julgamentos morais. Nas primeiras horas de vida, os recém-nascidos choram ao escutar outras crianças chorarem. Isso poderia indicar que elas nascem prontas para experimentar uma forma rudimentar de empatia (EISENBERG et al., 2003, p. 789). Antes de caminhar, crianças já são capazes de reconhecer e de valorar condutas como ajudar ou machucar terceiros. Hamlin, Wynn e Bloom (2007) mostraram a crianças com idades entre 6 e 10 meses uma encenação com fantoches na qual um desses tentava subir uma encosta. Em algumas das apresentações, o fantoche era ajudado por outro que o empurrava para cima. Em outras, um terceiro fantoche aparecia em cima da encosta e golpeava 
o fantoche que subia, impedindo-o de chegar ao topo. Após essas exibições, o fantoche que ajudava e o que atrapalhava eram postos em frente às crianças, e elas demonstravam uma forte preferência pelo primeiro. Segundo Haidt e Kesebir, essa experiência pode indicar a existência de um sistema de percepção capaz de criar emoções positivas em relação a quem ajuda, e emoções negativas em relação a quem prejudica terceiros 3 (HAIDT \& KESEBIR, 2010, p. 804).

\section{CRÍticas À TEORIA dAS FUNDAÇÕES MORAIS}

Os críticos da TFM costumam questionar a universalidade das supostas fundações morais. Jesse Prinz, e.g., contrariamente à ideia da universalidade da proibição de causar dano (harm), menciona vários casos envolvendo torturas, guerras e punições corporais (PRINZ, 2008, p. 373). Esse tipo de argumento não parece relevante contra o modelo defendido por Haidt, pois uma aversão a condutas que causam danos não implica uma proibição a toda e qualquer conduta que cause danos.

Nós não gostamos de ver outras pessoas em situações de aflição e sofrimento; vê-las em tais situações nos causa desconforto, o que demonstra uma predisposição a nos opormos a condutas lesivas. No entanto, Prinz acredita que esse tipo de predisposição não é moral. Ele destaca o valor comunicativo do grito de um membro da mesma espécie. $\mathrm{O}$ sofrimento dos outros nos alerta para o perigo, é um sinal de que há problema por perto. Por essa razão, não surpreende que ele nos provoque estresse (PRINZ, 2008, p. 374). Esse tipo de desconforto, ainda que possa estimular o comportamento pró-social, não seria propriamente moral.

Segundo Prinz, haveria três questões a serem perguntadas: 1) As fundações morais

3 Há outras experiências similares acerca da existência de uma base inata para o comportamento social: ver KINZLER et al. (2007) e WARNEKEN \& TOMASELLO (2006). são universais? 2) Elas podem ser aprendidas? 3) Elas são essencialmente morais? (PRINZ, 2008, p. 381). No que diz respeito à primeira pergunta, ele salienta que Haidt admite a variação de ênfase em diferentes culturas em relação às fundações. Isso traz a possibilidade de que alguma delas não seja concebida como moralmente significativa em todas as culturas (PRINZ, 2008, p. 381).

Prinz, no entanto, não apresenta evidências antropológicas significativas contrárias à afirmação da universalidade. Ele menciona apenas o caso dos Gahuku Gama, de Papua-Nova Guiné. Para esse povo, não seria imoral causar danos a outras pessoas, a menos que elas fizessem parte do grupo. De acordo com uma das interpretações possíveis, eles não moralizariam o sofrimento enquanto tal, mas apenas a hierarquia e a reciprocidade. Os Gahuku Gama acreditam que eles têm responsabilidades para com as pessoas que dependem deles e das quais eles dependem (PRINZ, 2008, p. 381-2).

Ainda que ele apresentasse algum caso específico mais forte contra a ideia das fundações morais, isso não invalidaria a teoria de Haidt. Essas fundações agem em um nível geral influenciando a conduta e estabelecendo vieses. Nada impede que a cultura atue contrabalanceando alguma dessas fundações. Nas grandes cidades ocidentais, por exemplo, acaba havendo uma ênfase em apenas duas fundações, a relacionada a danos e sofrimento e a relacionada à reciprocidade.

Prinz analisa também a questão do aprendizado. Segundo ele, nós somos dotados de emoções como empatia, respeito, raiva, nojo etc. Essas emoções seriam suficientes para explicar como os domínios (ou fundações) morais emergem ao longo do desenvolvimento. Quando uma sociedade, em razão de sentimentos de nojo ou repulsa, moraliza certos comportamentos, podemos afirmar que seus membros possuem um domínio de pureza em sua psicologia moral. Contudo, esse domínio seria apenas uma extensão aprendida de emoções não morais (PRINZ, 2008, p. 382). 
Por fim, Prinz entende que as fundações não são morais. Elas brotariam de emoções universais que teriam evoluído por diferentes razões e que não teriam sido selecionadas por favorecerem a ocorrência de julgamentos morais. Cada uma dessas emoções teria alguma aplicação não moral. Nós, por exemplo, sentimos empatia pelos doentes, mas não fazemos julgamentos morais sobre eles (PRINZ, 2008, p. 382). Segundo Prinz, emoções negativas adquirem significado moral apenas quando aquele que as possui apresenta emoções de culpa contra si mesmo ou contra terceiros (PRINZ, 2008, p. 382-3).

De maneira geral, todas as críticas de Prinz à TFM procuram demonstrar que as capacidades e características envolvidas nos julgamentos morais não são adaptações específicas à moralidade. Entretanto, esse tipo de argumento é relevante para a refutação do nativismo moral apenas quando se tem em mente uma concepção evolutiva de inato.

As definições de inato utilizadas no debate sobre o nativismo moral costumam agrupar-se em dois grupos principais: concepção evolutiva e concepção desenvolvimental (JOYCE, 2013, p. 532-33). De acordo com o primeiro grupo, "nativismo moral" equivale à afirmação de que a moralidade é uma adaptação no sentido darwiniano. Por sua vez, aqueles que adotam a concepção desenvolvimental consideram um traço inato quando o seu surgimento está protegido (canalizado) contra variações no ambiente onde ocorre o desenvolvimento do organismo.

Haidt procura explicar a partir de uma perspectiva evolucionista o surgimento das emoções relacionadas à moral e ele certamente considera que essas emoções surgiram como adaptações. Possivelmente, ele acredite que a capacidade para fazer julgamentos morais também seja uma adaptação, mas esse não é o aspecto mais relevante de seu modelo de nativismo moral. A teoria de Haidt indica que características humanas canalizadas, sejam elas adaptações ou efeitos secundários de adaptações, garantem que a moralidade se desenvolva e conserve certas características mesmo em ambientes muito distintos, ou seja, em grande medida ele adota uma concepção desenvolvimental de inato. Portanto, as críticas de Prinz não atingem alguns dos aspectos centrais da teoria elaborada por Haidt.

Defensores da Teoria da Gramática Moral Universal (GMU) costumam tecer outro tipo de crítica à TFM. ${ }^{4}$ Eles tendem a reconhecer a existência de vieses e a importância das emoções, mas classificam esses fatores como meras perturbações na faculdade moral. Hauser, e.g., reconhece que há um viés para favorecer membros do grupo e que ele pode funcionar como uma restrição às possíveis conformações das diversas moralidades. Ele admite que é difícil imaginar o surgimento de normas morais que privilegiem pessoas estranhas ao grupo em detrimento de membros do grupo. No entanto, ele tenta afastar esse viés, como se fosse um empecilho a uma teoria geral da moralidade (HAUSER, 2007, p. 133).

Chomsky, ao elaborar a sua teoria linguística, preocupou-se em identificar as regras empregadas por um falante ideal em uma comunidade linguística completamente homogênea, i.e., por alguém que não seja afetado por condições gramaticalmente irrelevantes, como limitações de memória, distrações e erros (CHOMSKY, 1965, p. 3). A partir daí, surge a distinção entre competência, i.e., o conhecimento que o falante-ouvinte tem de sua língua, e performance, i.e., o uso real da língua em situações concretas (CHOMSKY, 1965, p. 4).

De modo similar, Mikhail e Hauser procuram aplicar a distinção entre competência e performance em relação à faculdade moral. Para eles certas limitações psicológicas, informações prejudiciais, erros de performance e outros fatores distorceriam os julgamentos morais. A solução seria isolar esses fatores e identificar aqueles julgamentos morais que refletem a operação ideal da faculdade moral (MIKHAIL, 2011, p. 103). Os proponentes da GMU imaginam uma pessoa idealizada, capaz de empregar a sua faculdade moral

Sobre a Teoria da Gramática Moral, ver REX (2016b) e REX \& ABRANTES (2016). 
sem interferências de outras circunstâncias estranhas a essa faculdade. Em razão disso, Hauser, Mikhail e Dwyer, sob a influência de Rawls, buscam alcançar em seus experimentos uma posição neutra, capaz de possibilitar julgamentos morais que demonstrem a utilização plena da faculdade moral (RAWLS, 1971; MIKHAIL, 2011, p. 110).

No âmbito da linguagem, a separação entre faculdade linguística e fatores como a limitação imposta pela memória mostrou-se útil e esclarecedora do ponto de vista teórico (ROEDDER \& HARMAN, 2016, p. 4-5). No entanto, essa separação é problemática no caso da moral, pois não está claro se aquilo que eles consideram interferência não é na verdade constitutivo da moralidade. Por que deveríamos considerar que a moralidade se restringe a questões de justiça como eles parecem propor?

Há uma dificuldade em combinar a ideia de que os julgamentos morais obedecem a uma estrutura gramatical com a ideia de que as emoções desempenham um papel causal na produção das intuições morais. Mikhail, Hauser e Dwyer, embora reconheçam a existência de uma interface importante entre cognição e emoção, optam por defender que julgamentos morais causam emoções e não o contrário. Diante de evidências empíricas de que podemos manipular os julgamentos morais por meio da manipulação de emoções com a utilização de hipnose e de alterações ambientais (WHEATLEY \& HAIDT, 2005; SCHNALL et al., 2008), eles procuram preservar as suas teorias por meio da distinção entre competência e performance: as emoções afetariam apenas a performance moral, mas não seriam constitutivas da faculdade moral. Os processos emocionais desencadeados antes dos processos computacionais necessários à produção de julgamentos morais poderiam afetar os últimos e motivar a prática de certas ações, mas não seriam necessários (DWYER, HUEBNER \& HAUSER, 2010, p. 495). Há, no entanto, evidências de que respostas emocionais são necessárias à formação da moralidade. A ausência de empatia em crianças com tendências psicopáticas, e.g., interfere no desenvolvimento moral (BLAIR et al., 2006, 1997; DUPOUX \& JACOB, 2007, p. 376).

Embora os teóricos da GMU pretendam realizar uma abordagem descritiva da realização dos julgamentos morais, eles incluem em suas descrições certa visão normativa. Eles têm uma visão sobre qual deveria ser a moral vigente - essencialmente uma destinada a evitar injustiças (unfairness) e a produção de danos e sofrimento (harm) - e descartam as outras dimensões envolvidas nos julgamentos morais como se fossem interferências indevidas.

Outra crítica enfrentada por Haidt diz respeito à classificação proposta por ele para as fundações morais. Suhler e Churchland apontam para outros candidatos, como a modéstia, e.g., que seriam tão qualificados para assumir a posição de "domínio" ou "fundação" da moral quanto aqueles admitidos por Haidt. Os mais diversos grupos humanos possuem normas que restringem as ocasiões em que alguém pode vangloriar-se de suas conquistas e de sua posição social - aqueles que costumam gabar-se de seus feitos acabam sendo desprezados e rejeitados pelos seus pares (SUHLER \& CHURCHLAND, 2011, p. 2107). No entanto, o próprio Haidt admite que pode haver outras fundações da moral, além daquelas que ele propõe. Em trabalhos mais recentes (HAIDT, 2012), ele adotou uma nova classificação que divide a moralidade em seis fundações, em vez de cinco, e ele não exclui a possibilidade de reconhecer novas fundações. Assim, esse tipo de crítica poderia servir mais como uma forma de aprimoramento da teoria de Haidt do que como uma forma de refutação.

Há, contudo, outras falhas que parecem mais relevantes na TFM. Uma delas diz respeito à vinculação que Haidt faz entre cada uma dessas fundações com certas emoções. Ele associa, e.g., a emoção de raiva à fundação da reciprocidade. Mas a emoção de raiva pode ser despertada também pela violação de normas pertencentes a outras fundações: quando uma mãe enxerga alguém causando 
sofrimento a um de seus filhos (harm/care), há uma forte reação de hostilidade motivada também pela emoção de raiva. De forma análoga, as outras emoções, como ressentimento, nojo, repulsa, culpa, podem ser recrutadas em favor da imposição de normas pertencentes a domínios diversos. Portanto, não há uma justificativa plausível para associar, de modo isolado, um pequeno grupo de emoções a cada uma das fundações morais (SUHLER \& CHURCHLAND, 2011, p. 2107).

Por fim, analisarei, nas seções seguintes, as duas críticas que parecem mais pertinentes em relação à teoria elaborada por Haidt: o fato de ela estar comprometida com uma visão modular acerca da mente humana; e a sua incompletude, em razão de não fornecer uma explicação para as etapas mentais prévias ao desencadeamento das intuições.

\section{Modularidade da Mente}

O conceito de modularidade ganhou bastante notoriedade na Filosofia e na Psicologia desde que Fodor publicou o livro The Modularity of Mind (1983). Nesse livro, ele defendeu que muitos sistemas subjacentes à percepção e à linguagem são modulares (low-level systems, input systems). Por sua vez, adeptos da psicologia evolucionista (SPERBER, 2002; COSMIDES \& TOOBY, 1992; PINKER, 2009) elaboraram a tese de que a mente humana seria massivamente modular; ou seja, os sistemas cognitivos mais complexos (high-level cognition, central systems), responsáveis por funções como a solução de problemas, a fixação de crenças e planejamento também seriam modulares (ROBBINS, 2015).

No entanto, o conceito de modularidade tem significados distintos na teoria de Fodor e nas teorias dos psicólogos evolucionistas. Para Fodor, o encapsulamento das informações é uma característica indispensável dos módulos (FODOR, 2001). Isto é, um módulo, enquanto sistema cognitivo encapsulado, não pode ter acesso a informações armazenadas fora do módulo. A ilusão de Müller-Lyer oferece o exemplo clássico dessa propriedade
(Figura 1): ainda que estejamos convencidos de que as duas linhas centrais possuem o mesmo tamanho, em razão de as termos medido, continuamos a enxergar uma das linhas maior do que a outra em razão do encapsulamento de nosso sistema de percepção visual.

Figura 1: llusão de Müller-Lyer (ROBBINS, 2015).

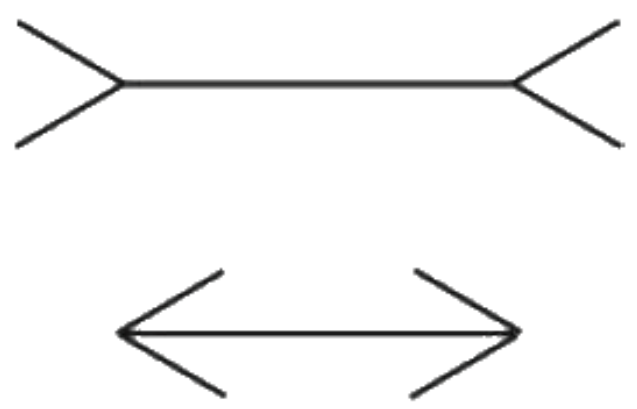

Já para aqueles que defendem a modularidade massiva, o encapsulamento não é uma característica necessária dos módulos (ROBBINS, 2015). De fato, eles não poderiam adotar o mesmo conceito de modularidade defendido por Fodor, pois não há como defender de maneira consistente que os sistemas cognitivos centrais sejam encapsulados, pois a fixação de crenças e as atividades de planejamento envolvem a utilização de informações dos mais diversos tipos. Por essa razão, até mesmo defensores do modelo de modularidade massiva, e.g. Peter Carruthers (2006, p. 12), admitem a incompatibilidade desse modelo com o conceito de módulo empregado por Fodor.

Dessa forma, os psicólogos evolucionistas procuram enfatizar a existência de domínios específicos, em vez de encapsulamento. Afirmar que um sistema qualquer é responsável por um domínio específico significa dizer que ele é dedicado exclusivamente ao processamento de uma matéria específica (SPERBER, 2005, p. 55-6). Nativistas, em geral, costumam invocar mecanismos de domínio específico para explicar a lacuna entre as informações fornecidas pela experiência e as ideias ou crenças que adquirimos a respeito do domínio ao 
qual pertencem essas informações (NICHOLS, 2005, p. 354-5). Mecanismos de domínio específico normalmente mencionados incluem aqueles dedicados à linguagem, ao reconhecimento de faces, à leitura de mentes e ao desenvolvimento de um senso comum nas áreas de física e biologia (HAUSER, 2007, p. 170s.; GELMAN, 1990; PREMACK, 1990).

Psicólogos evolucionistas, como regra, consideram que a nossa arquitetura cognitiva é composta por uma série de módulos que teriam evoluído para solucionar os problemas enfrentados pelos hominíneos ao longo do processo de evolução. 5 A adoção da modularidade é motivada pela observação de que nós resolvemos muitos de nossos problemas diários de maneira eficiente, sem a necessidade de refletirmos ou de empregarmos grandes esforços, e essa eficiência cognitiva demanda algum tipo de explicação. Psicólogos evolucionistas consideram que o ambiente no qual nossos ancestrais viviam apresentava uma série de desafios cognitivos recorrentes, mas que eram quase independentes uns dos outros. Cada um dos agentes de uma tribo precisava, e.g., identificar as ações que violavam as normas de seu grupo. Esse problema é desafiador, pois as regularidades nos comportamentos não são suficientes para resolvê-lo. É impraticável identificar o que é proibido simplesmente observando o que as outras pessoas do grupo não fazem. Dessa maneira, havia grande pressão seletiva no sentido de favorecer os indivíduos que tivessem adaptações específicas capazes de auxiliá-los nessa tarefa. Logo, módulos teriam surgido para auxiliar a resolver cada um dos diferentes tipos de problemas (um módulo para detectar cobras, outro módulo para reconhecer faces etc.). Assim, o aprendizado para solucionar cada um desses desafios seria canalizado e moldado por informações pré-instaladas pertencentes a domínios específicos (STERELNY, 2012).

A descrição do modelo de modularidade feita a seguir é ancorada em grande medida na descrição de STERELNY (2012).
Sperber emprega uma analogia com a distribuição de funções no corpo humano para defender a tese de que a mente humana é massivamente modular. A necessidade de enfrentar uma série de desafios ao longo da evolução levou os organismos complexos a desenvolverem subsistemas, como os diferentes órgãos do corpo humano, responsáveis por executar funções específicas. Segundo Sperber, algo semelhante teria ocorrido no nosso cérebro, ou seja, as estruturas que o compõem foram se diferenciando em módulos ao longo do tempo em razão de favorecerem a solução de problemas específicos enfrentados pelos hominíneos. Como esses módulos apresentam muitas diferenças entre si, em virtude de sua história evolutiva, seria inviável elaborar um conceito rígido de módulo (SPERBER, 2005, p. 54).

Haidt adota um modelo semelhante ao da modularidade massiva proposta por Sperber (2005), que inclui a existência de módulos de aprendizado capazes de produzir outros módulos mais específicos durante o desenvolvimento do indivíduo (HAIDT \& JOSEPH 2007, p. 379-80). Ou seja, haveria um módulo de aprendizado anterior a qualquer experiência para cada domínio moral — módulo de primeira ordem. Cada um desses módulos, a partir da experiência adquirida pelo indivíduo, produziria outros módulos de trabalho responsáveis por gerar as intuições morais perante situações específicas - módulos de segunda ordem. ${ }^{6}$

Os módulos de primeira ordem seriam adaptações para uma variedade de fenômenos, ameaças e oportunidades presentes por longos períodos no ambiente de nossos ancestrais, que teriam como função processar um tipo específico de entrada (input). Eles seriam responsáveis por atrair a atenção das pessoas para certos eventos - como demonstrações de crueldade e desrespeito e desencadeariam, a partir dos módulos de

\footnotetext{
6 Essa nomenclatura (second-order modules) é empregada por SUHLER \& CHURCHLAND (2011, p. 2.104).
} 
segunda ordem, reações intuitivas e emoções específicas: empatia, raiva etc. As variações culturais ocorreriam porque as culturas seriam capazes de restringir ou expandir os mecanismos que desencadeiam a atividade de cada um dos módulos de segunda ordem (HAIDT, 2012, cap. 6).

Um dos principais motivos que levam Haidt a acreditar na modularidade da mente humana é o fenômeno do moral dumbfounding. Ele utilizou essa expressão para designar as inúmeras situações que ocorreram em suas pesquisas, nas quais as pessoas condenavam moralmente uma conduta - praticar incesto utilizando dois métodos contraceptivos, masturbar-se com uma galinha morta etc. - , mas não conseguiam encontrar qualquer razão para justificar o julgamento, apenas o sentimento de que algo estava errado (2001).

Em inúmeros casos, os julgamentos morais permanecem inalterados apesar de serem apresentadas novas informações que invalidam as justificativas empregadas para sustentá-los. Haidt acredita que a explicação para esse fato é que os sistemas que produzem esses julgamentos são "em alguma medida encapsulados", i.e., ao contrário de Fodor, Haidt admite que os módulos tenham acesso a informações armazenadas em outros locais, mas de maneira limitada. Além disso, seguindo a posição normalmente adotada por psicólogos evolucionistas, Haidt acredita que os módulos dedicados à moralidade pertencem a domínios específicos.

Giroux chama a atenção para o fato de que não está muito claro como Haidt chegou à conclusão de que cada uma das cinco fundações da moral corresponde a um módulo mental diferente (GIROUX, 2011, p. 294-5). O simples fato de sermos capazes de classificar as intuições sobre a moral em cinco categorias, não justifica a crença de que cada uma delas seja implementada de forma independente ou por um mecanismo computacional discreto (MALLON, 2008, p. 151). As fundações propostas por Haidt podem talvez ser universais, mas isso não significa que existam cinco módulos especializados dedicados à moralidade (GIROUX, 2011, p. 294-5).

O raciocínio empregado por Haidt para concluir que os supostos módulos dedicados à moralidade são dedicados a domínios específicos segue um modelo de psicologia da "caixa-preta", na medida em que ele leva em consideração apenas relações de entrada (input) e saída (output). Haidt identifica um padrão de entradas e saídas - estímulos e comportamentos - e conclui que as saídas são o resultado do processamento de um módulo e que esse conjunto de entradas e saídas compõe o domínio ao qual esse módulo é dedicado (SUHLER \& CHURCHLAND, 2011, p. 2.106). Um dos problemas desse tipo de raciocínio é que ele não tem grande poder explicativo (ainda que esses módulos existissem, isso não nos diria muita coisa acerca de como eles funcionam) e pode ser utilizado de forma indiscriminada para qualquer processo cognitivo (basta identificar um padrão de entradas e saídas e concluir pela existência de mais um domínio específico). Embora Haidt esteja certo ao afirmar que algumas coisas são mais fáceis de aprender do que outras, esse fato não justifica a inferência de que essa facilidade de aprendizado seja fruto da existência de um módulo de aprendizado dedicado a um domínio específico. Poderiam ser elaboradas outras hipóteses que fossem mais consilientes com os resultados de estudos empíricos de outras áreas, como aqueles realizados em neurociência (SUHLER \& CHURCHLAND, 2011, p. 2.106).

$A$ ideia de que a mente humana seja composta por diversos mecanismos especializados para a solução de tipos particulares de problemas enfrenta forte oposição. Até mesmo Sperber reconhece que apenas uma minoria dos cientistas cognitivos acredita que a mente seja massivamente modular. Para a maioria deles, a mente é em grande medida não modular. Ainda que admitam a existência de alguns módulos relacionados à percepção, poucos defendem que os sistemas centrais de processamento sejam modulares (SPERBER, 2005, p. 53). 
Sterelny, e.g., acredita que uma mente massivamente modular não seria capaz de lidar com as grandes variações ambientais enfrentadas pelos hominíneos. Ele chama a atenção para a instabilidade física, biológica e social dos ambientes nos quais eles evoluíram. O tamanho dos grupos, o tipo de divisão de trabalho, a extensão das hierarquias sociais, as interações com outros grupos e espécies, os desafios ecológicos, nenhum desses fatores teria permanecido estável. Se a mente humana fosse preponderantemente um conjunto de módulos pré-programados, seria muito difícil explicar a grande plasticidade fenotípica demonstrada pelos hominíneos ao lidar com essas diferenças. A nossa mente se desenvolve de formas diferentes, adquirindo diversas habilidades e capacidades, dependendo do ambiente no qual estamos inseridos. As experiências culturais canalizam as nossas emoções de várias formas. Basta ver a diferença com a qual os insultos são percebidos em diferentes povos (NISBETT \& COHEN, 1996).

Sterelny reconhece a alta carga cognitiva dos desafios enfrentados no dia a dia dos hominíneos, mas contesta a premissa de que esses desafios eram estáveis e relativamente independentes. Ele destaca como nós erramos algumas vezes, mesmo que tenhamos sido expostos a uma série de exemplos; mas em outras circunstâncias somos capazes de responder com competência a novos problemas que demandam grande atividade cognitiva. Ele questiona como modelos modulares seriam capazes de explicar as respostas competentes aos problemas novos, pois, à medida que um modelo procura explicar as competências com base em informações pré-instaladas, ele perde poder explicativo em relação à competência demonstrada em face de novos desafios (STERELNY, 2012).

Sperber tenta responder a críticas desse tipo defendendo que o seu sistema de modularidade em dois níveis permitiria a flexibilidade necessária para lidar com as variações ambientais. Embora Sperber sustente que a mente é massivamente modular, a maioria desses módulos não seria anterior à aprendizagem. Um conjunto limitado de módulos de aprendizado presentes desde o nascimento propiciaria o surgimento de um número muito maior de módulos de trabalho encarregado de desempenhar as competências cognitivas. O surgimento desses diferentes módulos de segunda ordem dependeria das condições ambientais: diferentes condições provocariam o surgimento de módulos diferentes. Assim, a mente humana teria a capacidade de se moldar, ao longo de seu desenvolvimento, aos mais variados ambientes (SPERBER, 2005, p. 57-9).

No entanto, não há consiliência entre o modelo de modularidade proposto por Sperber e adotado por Haidt e os resultados empíricos de pesquisas neurocientíficas. Se a mente humana fosse composta por módulos, deveríamos esperar que a organização do cérebro fosse ao menos compatível com a existência desses módulos (SUHLER \& CHURCHLAND, 2011, p. 2.109). No entanto, a anatomia do nosso sistema nervoso central faz que as ideias de encapsulamento informacional e de especificidade de domínios sejam pouco plausíveis.

Embora as conexões locais presentes no córtex cerebral sejam densas, enquanto as conexões neurais que abrangem distâncias maiores são mais esparsas — "small world" architecture - , apenas algumas sinapses separam determinado neurônio de qualquer outro neurônio presente em nosso cérebro (SUHLER \& CHURCHLAND, 2011, p. 2.109). Esse padrão estaria presente até mesmo no córtex visual primário (V1), a área responsável por receber as entradas da retina por meio do núcleo geniculado lateral (NGL). Mais de $80 \%$ dos contatos sinápticos presentes em V1 não seriam oriundos do NGL, mas de outras regiões do cérebro (SUHLER \& CHURCHLAND, 2011, p. 2.109). Em razão disso, o funcionamento de $\mathrm{V} 1$ depende de diversos fatores. Niell e Stryker, e.g., demonstraram a influência que o sistema de locomoção exerce no córtex visual primário de ratos: as taxas de disparo dos neurônios de $\mathrm{V} 1$ dos animais quando eles estavam correndo era mais do que o dobro da taxa apresentada quando eles estavam em 
repouso (2010, p. 472). McCauley e Henrich, por sua vez, demonstram como as influências culturais alteram a percepção da ilusão de Müller-Lyer (2006). Resultados como esses desafiam a ideia de que as informações visuais estariam isoladas das informações presentes em partes distantes do cérebro.

A ideia de que os módulos seriam responsáveis por domínios específicos também enfrenta desafios semelhantes. Prinz, e.g., procura demonstrar que os exemplos normalmente mencionados de módulos não correspondem a domínios específicos. Ele aponta a dependência que a leitura de mentes tem em relação à memória de trabalho (PRINZ, 2006, p. 28). Prinz menciona a pesquisa conduzida por Mckinnon e Moscovitch, que demonstraram que o desempenho dos sujeitos cuja memória de trabalho era mantida ocupada era prejudicado em tarefas relacionadas à atribuição de crenças (MCKINNON \& MOSCOVITCH, 2007). Prinz destaca ainda como os estudos com neuroimagem mostram que a leitura de mentes envolve a utilização de diversas regiões do cérebro, sendo que cada uma dessas regiões contribui também para muitas outras capacidades, ou seja, não são específicas. Da mesma forma, os julgamentos morais recrutam diversas áreas do cérebro, inclusive aqueles centros normalmente associados às emoções (PRINZ, 2006, p. 29-30). Além dos estudos mencionados por Prinz, há outros que indicam que até regiões normalmente empregadas na percepção podem ser utilizadas para outras funções. V1, por exemplo, pode servir para decodificar uma língua, solucionar problemas ou realizar simulações mentais (KOSSLYN, GANIS \& THOMPSON, 2001; MELLET et al., 2000).

Haidt tem consciência das críticas direcionadas à modularidade. Em virtude disso, ele procura demonstrar que a existência de módulos não é um aspecto central de sua TFM. As fundações que ele propõe poderiam ser explicadas mais genericamente em termos de preparedness. A versão mais amena da teoria proposta por Haidt seria a seguinte: a mente humana foi moldada pela evolução de tal modo que as crianças aprendem com grande facilidade a se preocupar com a produção de danos a terceiros (harm), com a justiça (fairness), com a preservação dos membros de seus respectivos grupos (in-group), com a preservação da autoridade e com questões de pureza; no entanto, isso não significa que elas tenham qualquer conhecimento moral anterior à experiência, apenas que estão preparadas para adquirir certas crenças morais e para resistir a outras (HAIDT \& BJORKLUND, 2008, p. 204).

O que resta da teoria de Haidt, abandonada a ideia da modularidade, diz em suma que 1) temos mais facilidade em aprender algumas coisas do que outras; e 2) as nossas emoções desempenham um importante papel na determinação daquilo que temos mais facilidade de aprender. Essas afirmações não são muito controversas, pois é difícil imaginar como disposições como as nossas emoções básicas tristeza, raiva, nojo, medo etc. — não interfeririam no aprendizado e no desenvolvimento das normas sociais (GIROUX, 2011, p. 289). Todavia, esse tipo de afirmação não é suficiente para esclarecer muitas das nossas dúvidas a respeito do nativismo moral: Haidt afirma que a mente humana é preparada para aprender certas coisas, mas não oferece detalhes a respeito do que constitui essa organização que favorece o aprendizado. Ele não explica (no nível da psicologia cognitiva, da psicologia do desenvolvimento, da neurociência etc.) de que maneira os seres humanos são preparados para a aquisição de normas morais (SUHLER \& CHURCHLAND, 2011, p. 2.105). Haidt reafirma algo que já está implícito em diversas pesquisas empíricas sobre o comportamento humano, mas não desvenda os detalhes de como os processos cognitivos de nossa mente resultam na produção de juízos morais. Como veremos a seguir, a TFM não dá a devida atenção a elementos cognitivos prévios ao desencadeamento das emoções e intuições.

Antes de passarmos para essa etapa seguinte, destaco apenas que, de forma geral, as críticas apresentadas nesta seção servem também para a teoria da GMU, pois ela tam- 
bém está comprometida com a ideia de que a mente humana é modular. No entanto, ainda que eventualmente a mente humana seja em certa medida modular e, em especial, que a nossa capacidade linguística seja o resultado do funcionamento de algum módulo, existem diferenças entre a moral e a linguagem que tornam pouco plausível a tese de que nossa capacidade moral seja fruto da operação de determinados módulos.

A presença de reflexividade a partir de processos cognitivos conscientes com consequente alteração das intuições morais contraria a noção de "módulos morais". Uma das evidências a respeito da modularidade da competência gramatical seria a independência dos julgamentos acerca da gramaticalidade das sentenças em relação às crenças metalinguísticas (DUPOUX \& JACOB, 2007, p. 374-5). A descoberta do moral dumbfounding foi utilizada com o propósito de sustentar que algo semelhante ocorreria nos julgamentos morais. O fato de haver uma grande dissociação entre os julgamentos morais intuitivos e os processos deliberativos foi interpretado como favorecendo a hipótese de existência de um sistema computacional encapsulado subjacente aos julgamentos morais feitos pelas pessoas em geral (DWYER, HUEBNER \& HAUSER, 2010, p. 499).

Contudo, os processos de justificação moral também pertencem à capacidade moral humana — não há uma separação tão grande quanto ocorre na linguagem. A presença do moral dumbfounding não exclui a possibilidade de que pelo menos alguns julgamentos morais dependam das crenças explícitas que uma pessoa possui sobre a moralidade. É possível que alguém supere a intuição inicial que o leva a favorecer um membro do próprio grupo em nome de uma preferência explícita pela imparcialidade. Se os julgamentos morais podem sofrer a influência de crenças explícitas e de processos conscientes de reflexão, não pode haver um claro isolamento entre a capacidade moral e as crenças morais explícitas (DUPOUX \& JACOB, 2007, p. 374-5).

\section{REPRESENTAÇÃO MENTAL DA AÇÃO E TEORIA DA MENTE}

Mikhail e Hauser criticam Haidt por não incluir em seu modelo social-intuicionista uma etapa cognitiva prévia ao desencadeamento de emoções. Nenhuma criatura poderia simplesmente ter uma emoção sem que algo no cérebro houvesse reconhecido que aquela situação era digna de emoção. Haveria uma análise prévia, ainda que inconsciente, responsável por identificar as causas e consequências da ação e desencadear uma reação emocional. Todo esse processo ocorreria de maneira muito rápida, como quando os nossos cílios detectam a pressão de um objeto, e o nosso cérebro comanda o fechamento das pálpebras (HAUSER, 2007, p. 8). Eles destacam que ações muito parecidas ocasionam reações emocionais completamente diversas a depender de como elas são representadas ou percebidas por quem as assiste. Dependendo, por exemplo, das intenções que atribuímos ao autor, teremos reações distintas.

Essa crítica é em certa medida injusta, pois Haidt deixa claro que para ele a distinção relevante é aquela entre dois tipos de cognição - uma rápida (intuitiva) e outra lenta (raciocínio consciente) 一, não entre emoção e cognição, pois as emoções envolvem aspectos cognitivos. De qualquer forma, é necessário esclarecer quais processos ocorrem em nossas mentes desde o momento que percebemos uma ação até o momento em que formamos um julgamento moral sobre ela. Hauser e Mikhail parecem estar certos em afirmar que só é possível que uma ação produza determinada emoção após aquele que a percebe ter formado algum tipo de representação. Portanto, devemos buscar compreender como essa representação, as emoções e outros processos cognitivos mais lentos interagem. Uma explicação completa sobre como ocorrem os julgamentos morais deve esclarecer quais são as estruturas computacionais responsáveis por analisar o cenário em que a ação a ser julgada ocorre (DWYER, HUEBNER \& HAUSER, 2010, p. 494). 
Mikhail critica a passagem que Haidt faz em seu modelo social-intuicionista dos estímulos presentes em determinada situação para as intuições despertadas. O problema levantado por Mikhail é que os julgamentos morais não dependem apenas das propriedades superficiais de uma ação. Eles dependem também de um processo avaliativo prévio que determina a forma como essa ação é representada mentalmente, pois o cérebro gera representações da ação que vão além da informação dada (MIKHAIL, 2011, p. 38, 116 e 309-10).

Mikhail reconhece que as emoções estão claramente ligadas às intuições morais. No entanto, ele considera que o ponto relevante é fazer uma adequada caracterização do sistema de avaliação que essas intuições pressupõem (MIKHAIL, 2011, p. 122). Apenas emoções não poderiam explicar por que uma ação é considerada errada em um contexto, mas correta em outro. Para que uma emoção surja, algo deve provocá-la, algum sistema deve reconhecer uma ação, separá-la em partes e avaliá-la (HAUSER, 2007, p. 52-3). Esse processo avaliativo que desencadeia as emoções seria a primeira etapa da análise moral e poderia ser a etapa em que os julgamentos morais são formados, ou seja, a parte de nossa mente responsável por avaliar as intenções, ações e consequências poderia ser o centro no qual ocorrem as deliberações morais, a parte de nossa psicologia que julga inicialmente se um comportamento é permissível, obrigatório ou proibido. De acordo com essa visão, as emoções seriam desencadeadas por esses julgamentos morais feitos de maneira inconsciente. Elas não produziriam os julgamentos morais, apenas nos motivariam a agir de determinada forma (HAUSER, 2007, p. 30-1).

Segundo Hauser, Haidt explica o fenômeno do moral dumbfounding, apelando para a chamada "criatura humeana". Esse fenômeno ocorreria porque quando resolvemos dilemas morais não estaríamos raciocinando, mas manifestando intuições decorrentes de emoções. A criatura humeana falaria primeiro e a criatura "kantiana" viria a seguir, simples- mente para oferecer uma racionalização à decisão previamente tomada. Hauser defende que antes que as nossas emoções ou algum tipo de raciocínio consciente possam desempenhar algum papel nos julgamentos morais, deve haver uma etapa prévia de análise estrutural e avaliação das causas e consequências da ação - modelo da dita criatura "rawlsiana" (HAUSER, 2007, p. 156).

Quando julgamos moralmente, empregamos uma série de inferências sobre as intenções e os estados mentais do autor da ação. Entretanto, a capacidade para fazer essas inferências não pertence apenas ao campo da moral. Nós a empregamos quando interpretamos qualquer ação, por exemplo, quando vemos alguém cortando um limão e interpretamos que ele está fazendo uma limonada. A interpretação que fazemos de determinada ação pode provocar um sentimento de aversão ou de atração. Esse sentimento motiva a adoção de determinada reação e explica em boa parte como chegamos a um julgamento moral.

No entanto, a simples reação (e.g., aversão) a determinada circunstância não depende da existência de um julgamento moral. Até mesmo uma ameba é capaz de identificar certas características do ambiente onde se encontra - concentração de íons - e reagir aproximando-se ou se afastando. Quando nos deparamos com determinado ambiente ou com determinada ação também reagimos, afastando-nos ou nos aproximando, conforme as características que identificamos. Contudo, a simples reação emocional a determinada conduta não explica completamente o julgamento moral, pois esse envolve um elemento cognitivo diverso, uma crença a respeito do valor da ação interpretada. ${ }^{7}$

Em suma, a TFM, em sua versão amena, oferece uma explicação plausível para os julgamentos morais, mas falha ao não oferecer uma explicação detalhada. Todavia, talvez a explicação desses julgamentos não envolva

Sobre a relação entre julgamentos morais e crenças, ver REX (2017). 
muitos detalhes específicos à moralidade; i.e., talvez essa capacidade envolva basicamente uma capacidade geral para reconhecer padrões, o que possibilitaria ao indivíduo identificar as normas de seu grupo, conjugada com uma tendência a moralizar determinados tipos de comportamento. Haveria uma tendência de certos tipos de normas se estabelecerem nas sociedades em razão de predisposições emocionais tipicamente humanas e uma vez estabelecidas essas normas, os novos indivíduos seriam capazes de aprendê-las por mecanismos gerais de aprendizado.

\section{CONSIDERAÇões FinaIS}

A capacidade para fazer julgamentos morais surge muito cedo e de forma robusta em diversos ambientes. Essa facilidade de aprendizado sugere que o cérebro humano está de alguma forma preparado para aprender normas morais. Além disso, as normas morais existentes nas diferentes comunidades que conhecemos se agrupam em torno dos mesmos temas. Esses fatos constituem indícios fortes em favor da existência de uma base biológica responsável por produzir certos vieses no aprendizado moral.

A TFM, proposta por Haidt, tem o mérito de incluir certas características psicológicas típicas da espécie humanas, como as nossas disposições emocionais, na explicação sobre a nossa capacidade para julgar moralmente.
No entanto, ela também é vulnerável a críticas importantes. Em primeiro lugar, ao aceitar a tese da modularidade massiva, Haidt se compromete com uma visão a respeito da mente humana que não é consiliente com os resultados de pesquisas neurocientíficas. Apesar disso, Haidt busca deixar claro que esse não é o aspecto mais relevante do seu modelo de nativismo.

Em razão de ter ciência das críticas à modularidade massiva, ele propõe subsidiariamente uma versão mais amena de sua teoria. Conforme essa versão, as fundações morais poderiam ser explicadas mais genericamente em termos de preparação (preparedness). Haidt sustenta que características humanas canalizadas garantem que a moralidade se desenvolva e conserve certas características mesmo em diferentes ambientes.

A teoria de Haidt sofre ainda críticas em razão de sua incompletude. Ela não fornece uma explicação para as etapas mentais prévias ao desencadeamento das intuições e, nesse sentido, parece ignorar que só é possível que uma ação produza determinada intuição após aquele que a percebe ter formado algum tipo de representação. Portanto, em sua versão amena, a TFM oferece uma explicação plausível para os julgamentos morais, mas falha ao não oferecer uma explicação a respeito do papel que inferências a respeito das intenções e dos estados mentais do autor da ação desempenham no desencadeamento das intuições morais.

\section{REFERÊNCIAS}

ATRAN, S. Folk biology and the anthropology of science: cognitive universals and cultural particulars. The behavioral and brain sciences, 1998, v. 21, n. 4, p. 547-569-609.

AYALA, F. J. The difference of being human: morality. Proceedings of the national academy of sciences of the United States of America, 2010. v. 107. Suppl., p. 9.015-9022.

BLAIR, R. J. R. et al. The development of psychopathy. Journal of child psychology and psychiatry, 2006, v. 47, n. 3-4, p. 262-276.

BROWN, D. E. Human universals. Philadelphia: Temple University Press, 1991. 
CARRUTHERS, P. The architecture of the mind, 1. ed. Oxford: Clarendon Press, 2006.

CHOMSKY, N. Aspects of the theory of syntax. Cambridge: The MIT Press, 1965.

. The logical structure of linguistic theory. New York: Springer, 1975.

. Knowledge of language: its nature, origins, and use. New York: Praeger, 1986.

COSMIDES, L.; TOOBY, J. Cognitive adaptations for social exchange. In: BARKOW, J. H.; COSMIDES, L.; TOOBY, J. (Org.). The adapted mind: evolutionary psychology and the generation of culture. New York: OUP, 1992, p. 163-228.

DUPOUX, E.; JACOB, P. Universal moral grammar: a critical appraisal. Trends in cognitive sciences, 2007, v. 11, n. 9, p. 373-378.

DWYER, S.; HUEBNER, B.; HAUSER, M. D. The linguistic analogy: motivations, results, and speculations. Topics in cognitive science, 2010, v. 2, n. 3, p. 486-510.

EISENBERG, N.; LOSOYA, S.; SPINRADD, T. Affect and prosocial responding. In: DAVIDSON, R. J.; SHERER, K. R.; GOLDSMITH, H. H. (Org.). Handbook of affective sciences, 1. ed. New York: OUP, 2003, p. 787-803.

EKMAN, P.; SORENSON, E. R.; FRIESEN, W. V. Pan-cultural elements in facial displays of emotion. Science, 1969. v. 164, n. 3.875, p. 86-88.

FISKE, A. P. The four elementary forms of sociality: framework for a unified theory of social relations. Psychological review, 1992, v. 99, n. 4, p. 689-723.

FODOR, J. A. The modularity of mind: an essay on faculty psychology. Cambridge: MIT Press, 1983.

. The mind doesn't work that way: the scope and limits of computational psychology, 1. ed. Cambridge: A Bradford Book, 2001.

GELMAN, R. First principles organize attention to and learning about relevant data: number and the animate-inanimate distinction as examples. Cognitive science, 1990. v. 14, n. 1, p. 79-106.

GIROUX, J. The origin of moral norms: a moderate nativist account. Dialogue, 2011, v. 50, n. 2, p. 281-306.

HAIDT, J. The emotional dog and its rational tail: a social intuitionist approach to moral judgment. Psychological review, 2001, v. 108, n. 4, p. 814-834.

. The righteous mind: why good people are divided by politics and religion, 1. ed. New York: Pantheon Books, 2012.

. BJORKLUND, F. Social intuitionists answer six questions about morality. In: SINNOTT-ARMSTRONG, W. (Org.). Moral psychology. Cambridge: MIT Press, 2008, v. 2, p. 181-217.

. JOSEPH, C. Intuitive ethics: how innately prepared intuitions generate culturally variable virtues. Daedalus, 2004, v. 133, n. 4, p. 55-66.

. The moral mind: how five sets of innate intuitions guide the development of

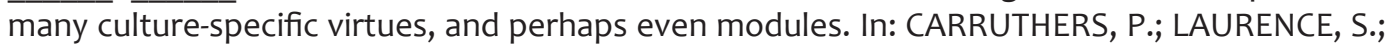
STICH, S. (Org.). The innate mind. New York: OUP, 2007, v. 3, p. 367-392.

. KESEBIR, S. Morality. In: FISKE, S.; GILBERT, D.; LINDZEY, G. (Org.). Handbook of social psychology, 5. ed. Hoboken: Wiley, 2010, p. 797-832. 
HAMLIN, J. K.; WYNN, K.; BLOOM, P. Social evaluation by preverbal infants. Nature, 2007, v. 450, n. 7.169, p. 557-559.

HAUSER, M. D. Moral minds: the nature of right and wrong. New York: Harper Collins, 2007.

JOYCE, R. The evolution of morality. Cambridge: MIT Press, 2006.

. The many moral nativisms. In: STERELNY, K. et al. (Org.). Cooperation and its evolution. Cambridge: MIT Press, 2013, p. 549-572.

KINZLER, K. D.; DUPOUX, E.; SPELKE, E. S. The native language of social cognition. Proceedings of the national academy of sciences of the United States of America, 2007, v. 104, n. 30, p. 12.577-12.580.

KOSSLYN, S. M.; GANIS, G.; THOMPSON, W. L. Neural foundations of imagery. Nature Reviews, 2001, v. 2, n. 9, p. 635-642.

LOCKE, J. An essay concerning human understanding. Amherst: Prometheus Books, 1995.

MALLON, R. Reviving rawls's linguistic analogy inside and out. In: SINNOTT-ARMSTRONG, W. (Org.). Moral psychology. Cambridge: MIT Press, 2008, v. 2, p. 145-156.

MCCAULEY, R. N.; HENRICH, J. Susceptibility to the müller-lyer illusion, theory-neutral observation, and the diachronic penetrability of the visual input system. Philosophical psychology, 2006, v. 19, n. 1, p. 79-101.

MCKINNON, M. C.; MOSCOVITCH, M. Domain-general contributions to social reasoning: theory of mind and deontic reasoning re-explored. Cognition, 2007, v. 102, n. 2, p. 179-218.

MELLET, E. et al. Functional anatomy of high-resolution visual mental imagery. Journal of cognitive neuroscience, 2000, v. 12, n. 1, p. 98-109.

MIKHAIL, J. M. Elements of moral cognition: rawls' linguistic analogy and the cognitive science of moral and legal judgment. Cambridge: Cambridge University Press, 2011.

NICHOLS, S. Innateness and moral psychology. In: CARRUTHERS, P.; LAURENCE, S.; STICH, S. (Org.). The innate mind. New York: OUP, 2005, v. 1, p. 353-370.

NIELL, C. M.; STRYKER, M. P. Modulation of visual responses by behavioral state in mouse visual cortex. Neuron, 2010, v. 65, n. 4, p. 472-479.

NISBETT, R. E.; COHEN, D. Culture of honor: the psychology of violence in the south, 1. ed. Boulder: Westview Press, 1996.

PINKER, S. How the mind works. New York: W. W. Norton, 2009.

PLATÃO. Meno and other dialogues. Trad. Robin Waterfield. Oxford: OUP, 2005.

PREMACK, D. The infant's theory of self-propelled objects. Cognition, jul. 1990, v. 36, n. 1, p. 1-16.

PRINZ, J. Is the mind really modular. In: STAINTON, R. J. (Org.). Contemporary debates in cognitive science. Oxford: Blackwell, 2006, p. 22-36.

. Is morality innate. In: SINNOTT-ARMSTRONG, W. (Org.). Moral psychology. Cambridge: MIT Press, 2008, v. 1, p. 367-406.

RAWLS, J. A theory of justice. Cambridge, Mass.: Harvard University Press, 1971. 
REX, R. V. DE V. O Debate sobre o Nativismo Moral: Desenvolvimento e Evolução da Moralidade. p.180. Dissertação (Mestrado em Filosofia), Brasília: Universidade de Brasília, 2016a.

. Gramática moral universal: controvérsias a respeito da analogia lingüística. Principia: an international journal of epistemology, 2016b. v. 20, n. 2, p. 255-283.

. Ética evolucionista: a diferença entre altruísmo e moralidade. Revista Dissertatio de Filosofia, 2017. v. 44, n. 0, p. 105-130.

REX, R. V. DE V.; ABRANTES, P. C. Moral Nativism: Some Controversies. Dialogue: Canadian Philosophical Review / Revue canadienne de philosophie, 2016. 1., v. 56, p. 1-24.

ROBBINS, P. Modularity of mind. In: ZALTA, E. N. (Org.). The Stanford Encyclopedia of Philosophy. Summer 2015 ed. Disponível em: http://plato.stanford.edu/archives/sum2015/entries/ modularity-mind/. Acesso em: 31 out. 2016.

ROEDDER, E.; HARMAN, G. Moral grammar, 2016. Disponível em: http://www.princeton. edu/ harman/Papers/Moral_Grammar.pdf. Acesso em: 31 out. 2016.

ROZIN, P. et al. The CAD triad hypothesis: a mapping between three moral emotions (contempt, anger, disgust) and three moral codes (community, autonomy, divinity). Journal of personality and social psychology, 1999, v. 76, n. 4, p. 574-586.

SAMET, J. The historical controversies surrounding innateness. In: ZALTA, E. N. (Org.). The Stanford Encyclopedia of Philosophy. Fall 2008 ed. Disponível em: http://plato.stanford.edu/ archives/fall2008/entries/innateness-history/. Acesso em: 26 nov. 2016.

SCHNALL, S. et al. Disgust as embodied moral judgment. Personality and social psychology bulletin, 2008, v. 34, n. 8, p. 1.096-1.109.

SCHWARTZ, S. H.; BILSKY, W. Toward a theory of the universal content and structure of values: extensions and cross-cultural replications. Journal of personality and social psychology, 1990, V. 58, n. 5, p. 878-891.

SHWEDER, R. A. et al. The "big three" of morality (autonomy, community, divinity) and the "big three" explanations of suffering. In: BRANDT, A.; ROZIN, P. (Org.). Morality and health. New York: Routledge, 1997, p. 119-169.

SPELKE, E. S. The origins of physical knowledge. In: WEISKRANTZ, L. (Org.). Thought without language. Oxford; New York: OUP, 1988, p. 168-184.

SPERBER, D. In defense of massive modularity. In: DUPOUX, E. (Org.). Language, brain and cognitive development. Cambridge: MIT Press, 2002, v. 47, p. 47-58.

. Modularity and relevance: how can a massively modular mind be flexible and contextsensitive? In: CARRUTHERS, P.; LAURENCE, S.; STICH, S. (Org.). The innate mind. New York: OUP, 2005, v. 1, p. 53-68.

STERELNY, K. The evolved apprentice. Cambridge: MIT Press, 2012.

SUHLER, C. L.; CHURCHLAND, P. Can innate, modular "foundations" explain morality? challenges for haidt's moral foundations theory. Journal of cognitive neuroscience, 2011, v. 23, n. 9, p. 2.103-2.116-2.122.

WAAL, F. DE. Good natured: the origins of right and wrong in humans and other animals. Cambridge: Harvard University Press, 1996. 
WARNEKEN, F.; TOMASELLO, M. Altruistic helping in human infants and young chimpanzees. Science, 2006, v. 311, n. 5.765, p. 1.301-1.303.

WHEATLEY, T.; HAIDT, J. Hypnotic disgust makes moral judgments more severe. Psychological science, 2005, v. 16, n. 10, p. 780-784.

\section{SOBRE O AUTOR}

\section{ROGer VALÉRIO de VARGas ReX}

Mestre em Filosofia pela Universidade de Brasília (2016). Especialista em Direito Constitucional. Bacharel em Ciências Jurídicas e Sociais pela Universidade Federal do Rio Grande do Sul (2011). Ex-Professor voluntário da Faculdade de Direito da Universidade de Brasília e integrante do Grupo de Pesquisa Mente, Linguagem e Evolução.

E-mail: rogervargasrex@gmail.com

Recebido em: 25/09/2017

Aprovado em: 30/01/2018 